\title{
ENHANCED FLIGHT VISION SYSTEMS OPERATIONAL FEASIBILITY STUDY USING RADAR AND INFRARED SENSORS
}

\author{
Timothy J. Etherington, Rockwell Collins, Hampton, Virginia \\ Lynda J. Kramer, Kurt Severance, Randall E. Bailey, Steven P. Williams, Stephanie J. Harrison, NASA \\ Langley Research Center, Hampton, Virginia
}

\begin{abstract}
Approach and landing operations during periods of reduced visibility have plagued aircraft pilots since the beginning of aviation. Although techniques are currently available to mitigate some of the visibility conditions, these operations are still ultimately limited by the pilot's ability to "see" required visual landing references (e.g., markings and/or lights of threshold and touchdown zone) and require significant and costly ground infrastructure. Certified Enhanced Flight Vision Systems (EFVS) have shown promise to lift the obscuration veil. They allow the pilot to operate with enhanced vision, in lieu of natural vision, in the visual segment to enable equivalent visual operations (EVO).
\end{abstract}

An aviation standards document was developed with industry and government consensus for using an EFVS for approach, landing, and rollout to a safe taxi speed in visibilities as low as 300 feet runway visual range (RVR). These new standards establish performance, integrity, availability, and safety requirements to operate in this regime without reliance on a pilot's or flight crew's natural vision by use of a fail-operational EFVS. A pilot-in-the-loop high-fidelity motion simulation study was conducted at NASA Langley Research Center to evaluate the operational feasibility, pilot workload, and pilot acceptability of conducting straight-in instrument approaches with published vertical guidance to landing, touchdown, and rollout to a safe taxi speed in visibility as low as 300 feet RVR by use of vision system technologies on a head-up display (HUD) without need or reliance on natural vision. Twelve crews flew various landing and departure scenarios in 1800, 1000, 700, and 300 RVR. This paper details the non-normal results of the study including objective and subjective measures of performance and acceptability. The study validated the operational feasibility of approach and departure operations and success was independent of visibility conditions.
Failures were handled within the lateral confines of the runway for all conditions tested. The failoperational concept with pilot in the loop needs further study.

\section{Introduction}

Ever since the Wright Brothers were tired of flying in circles around Huffman Field and wanted to use the airplane to go somewhere, the problem of reduced visibility has been an issue. Lindbergh said "Aviation will never amount to much until we learn to free ourselves from the mists. What I really need is a pair of spectacles to see through the fog. If I had a device like that, how simple the entire flight would be!"' Even though aviation has likely eclipsed his imagination, the problem of reduced visibility still plagues the industry and complex instrument landing systems are used as crutches to replace pilot vision for landing. Currently, the U.S. air transportation system is undergoing a transformation to accommodate the movement of large numbers of people and goods in a safe, efficient, and reliable manner. ${ }^{2}$ One of the key capabilities envisioned to achieve this Next Generation Air Transportation System (NextGen) is the concept of equivalent vision operations (EVO). EVO is the ability to achieve the safety of current-day Visual Flight Rules (VFR) operations and maintain the operational tempos of VFR irrespective of the weather and visibility conditions. As visibilities decrease, instrument landing systems become increasingly complex and require:

- additional training, experience, and currency for the crew

- additional aircraft systems including auto land and auto throttle with associated maintenance costs 
- additional airport ground infrastructure including paint and signage and sophisticated approach and centerline lighting systems often with individual controls

- additional procedure design and charting procedures often with multiple procedures for each runway end

Each of these items represents a significant burden to operators, airports, and regulators; and collectively are one reason for the limited availability of low visibility instrument approach procedures. As of April 2015, there were 1,277 Instrument Landing System (ILS) instrument approach procedures (IAPs) to Category I minima (no lower than $200 \mathrm{ft}$ [61 m] decision height, $2400 \mathrm{ft}[731.5 \mathrm{~m}]$ visibility) available throughout the United States; but only 153 Category II (no lower than $100 \mathrm{ft}[30.5 \mathrm{~m}]$ decision height, $1200 \mathrm{ft}$ [366 m] visibility); and 118 Category III (a decision height lower than $100 \mathrm{ft}$, or no decision height, or a runway visual range (RVR) less than $1200 \mathrm{ft}$ ) IAPs. ${ }^{3}$ Enhanced Fight Vision Systems (EFVS) may eliminate much of the ground infrastructure and charting requirements since it is used in the "visual" segment of the instrument approach. It provides a head-up, eyes out, manual flown procedure that is exactly the same for each approach and landing, regardless of the visibility conditions. Pilots, in essence, practice for low visibility operations during all takeoffs and landings since the visual picture and operation procedures are unaffected by the visibility conditions.

EFVS is a significant part of the FAA NextGen Implementation Plan for improved approaches and low-visibility operations. ${ }^{4}$ NASA Langley Research Center is conducting research to ensure effective technology development and implementation of regulatory and design guidance to support introduction and use of onboard Synthetic Vision Systems (SVS)/EFVS advanced flight deck vision system technologies in NextGen operations.

\section{Background}

SVS is a computer-generated image of the external scene topography that is generated from aircraft attitude, high-precision navigation, and data of the terrain, obstacles, cultural features, and other required flight information. EFVS is a real-time electronic image of the external scene generated by imaging sensors, such as a Forward-Looking InfraRed (FLIR) or Millimeter Wave Radar (MMWR), and presented on a head-up display (HUD). Both SVS and EFVS are onboard visionbased technologies intended to supplement or enhance the natural vision of the pilot in low visibility conditions. Combined Vision Systems (CVS) use a combination of SVS and EFVS for presentation to the pilot.

NASA, Rockwell Collins, and others have developed and shown that SVS technologies provide significant improvements in terrain awareness and reductions for the potential of Controlled-Flight-IntoTerrain incidents/accidents, ${ }^{5,6,7}$ improvements in flight technical error to meet Required Navigation Performance criteria, ${ }^{8,9,10}$ and improvements in situation awareness without increased workload compared to current generation cockpit technologies. ${ }^{11,12,13}$ As such, SVS, often displayed on a head-down display (HDD), is emerging as standard equipage for Part 23 and Part 25 flight decks even though, to date, no operational credit is obtained from equipage. ${ }^{14}$

EFVS capability on a HUD using FLIR sensor technology has garnered a significant share of the business aircraft market and is growing in Part 121 and 135 operations. ${ }^{15}$ EFVS provides many of the same operational benefits as SVS technology, but it uses a real-time view of the external environment, independent of the aircraft navigation solution or database. These differences, in part, enable operational credit with use of an approved EFVS. In 2004, Title 14 of the Code of Federal Regulations (CFR) Section (§) 91.175 was amended to enable operators conducting straight-in instrument approach procedures (in other than Category II or Category III operations) to descend below the published Decision Altitude (DA), Decision Height (DH), or Minimum Descent Altitude (MDA), down to 100 feet above touchdown zone elevation (TDZE) using an approved EFVS in lieu of natural vision. (To descend below 100 feet above the TDZE, the required visual references for landing must be distinctly visible and identifiable by the pilot using natural vision.) An approved EFVS must meet the requirements of $\$ 91.175(\mathrm{~m})$ and the use of a HUD or an equivalent display is essential and required by regulation. 
Synthetic and Enhanced Vision Systems (SEVS) technologies, such as SVS/EFVS in combination with HDD/HUD, form the basis for an electronic display of visual flight references for the flight crew. Integrating these SEVS displays with conformal symbology provides important situation, guidance, and/or command information as necessary and/or appropriate to enable all weather approach and landing operations. The primary reference for maneuvering the airplane is based on what the pilot sees electronically through the SEVS, in lieu of or supplemental to the pilot's natural vision, in low visibility conditions.

The key concept for 14 CFR $\S 91.175$ is that an EFVS can be used in lieu of natural vision from the DA/DH/MDA to $100 \mathrm{ft}$ height above the TDZE provided the visibility of the enhanced vision image meets or exceeds the published visibility required for the approach being flown and the required visual references are clearly identified. Minimum aviation system performance standards for EFVS are available in RTCA DO-315. ${ }^{16}$ RTCA DO-315 also provides performance standards for SVS but without operational credit.

The FAA has started a rulemaking project ${ }^{17}$ to expand operational credit for EFVS beyond what is currently authorized under 14 CFR $\$ 91.175$. Specifically, the new regulation (14 CFR \$91.176) will cover instrument approaches with EFVS, enabling landings without natural vision. The proposed rule would permit an EFVS to be used in lieu of natural vision during a straight-in precision instrument approach procedure (Category I, II and III) or an approach with approved vertical guidance. Current EFVS operations are limited to straight-in instrument approaches procedures (in other than Category II or Category III operations). The new rule would permit EFVS to be used during touchdown and rollout and would also add operational benefits for Part 91K, 135, and 121 operators with new capabilities with EFVS. 14 CFR \$135.219 would be amended to allow dispatch to a destination that is below minimums if the aircraft is EFVS equipped and the operator is authorized for EFVS operations through OpSpecs (Operations Specifications), MSpecs (Management Specifications), or LOA (Letters of Authorization). Also, 14 CFR $\$ 135.225$ would be modified to enable an EFVS equipped aircraft and trained crew to initiate or continue an approach when the destination airport is below standard authorized minimums. Similar rules will be changed in CFR Part 121 to allow operation for scheduled air carriers. These upcoming rule changes support EVO through use of onboard flight-deck based EFVS rather than necessitating additional ground infrastructure equipment and operating procedures. An EFVS-equipped aircraft and qualified crew could dispatch and continue an approach to a landing, even when the destination airport is below standard authorized minimums, solely through the use of an electronic (sensor) image since natural vision is no longer required with EFVS. ${ }^{18}$

The FAA proposed EFVS rule change does not explicitly impose an RVR limitation but mentions that initial implementations of EFVS operations to touchdown and rollout may be limited to visibilities of no lower than 1000 RVR because airworthiness and certification criteria have not been developed to support EFVS operations below 1000 RVR. Past NASA simulation and flight test research ${ }^{19,20,21,22}$ supports the viability of this expanded EFVS operational credit where it was shown that using a single sensor EFVS (FLIR imagery on a HUD) to hand-fly approaches through touchdown resulted in excellent localizer tracking performance and an improvement in glideslope tracking performance in visibility as low as 1000 RVR. All currently approved EFVS use FLIR (single sensor imagery) on a HUD. Natural vision of 700 to $1000 \mathrm{ft}$ RVR has been shown to be sufficient to mitigate a complete failure of the single sensor EFVS. FLIR is dependent upon atmospheric conditions. It works well in smoke, haze, and at night; but has degraded performance in fog, rain, and snow.

RTCA DO- $341^{23}$ was drafted to establish minimum performance standards for EVFS operations on straight-in instrument approach procedures with published vertical guidance to touchdown, landing, and roll-out to a safe taxi speed in visibility as low at $300 \mathrm{ft}$ RVR. In this operation, criteria are established such that the combination of all systems used during the EFVS operation shall be designed, tested, and certified to a level of safety appropriate for the phase of flight and the intended operation. As such, a fail-operational EFVS design is necessary - consistent with other systems and subsystems used for the same intended function and phase of flight (e.g., instrument landing systems, 
autoland systems, and navigation systems) - without the need or reliance of the crew's natural vision. In these extremely low visibility conditions, there is not sufficient natural vision for the flight crew to mitigate certain EFVS failure conditions which might have catastrophic consequences.

DO-341 specifies that both the PF and pilotmonitoring (PM) are required to have an independent EFVS HUD as well as an alternate display for enhanced vision (EV) sensor imagery. It is envisioned that more than one sensor will be needed for EFVS operations below $1000 \mathrm{ft}$ RVR. FLIR sensor technology used in production EFVS is limited in its ability to work in extreme low visibility conditions, such as ground fog. Millimeter wave radar (MMWR) technologies show promise for working in operationally relevant atmospheric conditions, but the image resolution is not as good as natural vision.

A pilot-in-the-loop high-fidelity motion simulation study was conducted at NASA Langley Research Center to evaluate the operational feasibility, pilot workload, and pilot acceptability of conducting straight-in instrument approaches with published vertical guidance to landing, touchdown, and rollout to a safe taxi speed in visibility as low as 300 feet RVR by use of vision system technologies on a head-up display (HUD) without need or reliance on natural vision. Twelve crews flew various landing and departure scenarios in 1800, 1000, 700, and 300 RVR.

This paper details the non-normal results of the study including objective and subjective measures of performance and acceptability. Due to paper length restrictions, an additional paper details the normal results for this study. ${ }^{24}$

The study attempted to determine if the failoperational concept detailed in RTCA DO-341 was operationally feasible. The concept in automated systems is that no single failure should cause a goaround below a specified altitude, called an alert height. For an EFVS system designed for $300 \mathrm{ft}$ RVR conditions, the alert height was coincident with the decision height/decision altitude as per DO-341.

The RTCA SC-213 committee discussed a number of methods that a fail operational-like system could be implemented with a manual flown approach.
The committee agreed that dual HUDs, dual PFDs, and redundant sensors would be required. If any of the required EFVS systems or subsystems fail above the DA/DH and result in a loss of reliability, a failure annunciation would be given and the crew would execute a go-around since a fail-operational capability is not ensured. If any of the PF systems failed below the $\mathrm{DA} / \mathrm{DH}$, the fail-operational capability that is designed for beyond this pointwould mean that he/she could transfer control to the pilot monitoring or he/she could switch to a different sensor or different display and continue the landing. Optionally, he/she could also go-around but that defeats the purpose of fail-operational.

The study was designed with dual HUD and dual PFD displays, all with redundant sensor information on the displays. Pilots were briefed and trained that for any failure of the HUD they could transition to head-down, they could transfer control to the other pilot, or they could go-around. They were to choose the safest course of action. In an attempt to determine how pilots would handle the failures without dictating specific procedures or forcing them to do something against their normal standard operating procedures, the crew were specifically not trained for the failures in order to get an unrehearsed reaction. The fail-operational discussion occurred twice during the pre-test briefing.

\section{Method}

\section{Participants}

Twenty-four pilots were recruited representing various operators. Each pilot was required to hold an Airline Transport Pilot rating, recent HUD experience with at least 100 hours of HUD experience as pilot in command, enhanced vision (EVS) or EFVS experience, and glass cockpit experience. Crews were recruited as pairs from the same employer to minimize inter-crew conflicts in Standard Operating Procedures (SOPs) and Crew Resource Management (CRM) procedures or training. Eight crews were recruited from various passenger airlines, one crew was recruited from FedEx, and three crews were from the business aviation community. The business aviation crews had the most recent experience with EFVS. Recent HUD and EVS experienced ranged from "currently flying 
EFVS on the line" to "I last used it twelve years ago in the military". The Captains' average age was 57.7 years with an average of 1,988 HUD flight hours, 23 years of commercial flying, and 14.8 years of military flying. The First Officers' average age was 49.7 years with an average of 1,255 HUD flight hours, 14.8 years of commercial flying, and 14 years of military flying. The Captain was the designated PF throughout all the trials and the First Officer served as the PM.

\section{Experimental Design}

The study used a partial $7 \times 2 \times 4$ randomized block design for approaches. See Figure 1, Nominal Approach Matrix for a description of cross effects. This design resulted in 18 nominal approach scenarios. The crews also flew three additional approaches with the following failures:

- PF complete HUD failure was presented using the Blended EFVS concept in 300 RVR with 10 knots of right cross-wind on Runway $18 \mathrm{~L}$

- PM HUD failure was presented using the Slant Range EFVS concept in 700 RVR with 10 knots of left cross-wind on Runway 36R

- EFVS system failure was tested in 700 RVR on Runway 36C with betweensubject testing presented on either Blended EFVS concept or Blended with SVS EFVS concept

The study used a partial $5 \times 2$ randomized block design for departures. See Figure 2, nominal departure matrix for a description of cross effects. The conventional HUD symbology-only baseline (no imagery) was tested in 300 RVR on a runway with centerline lighting. The EFVS concepts were tested without centerline lights in 300 RVR to test the elimination of lighting requirements for departure operations. An engine failure on departure was used to force a rejected takeoff (RTO) and this condition was tested twice, once with the Slant Range EFVS concept and once with the conventional HUD symbology, with the failure order counterbalanced. This resulted in seven departure scenarios total with two resulting in an RTO.

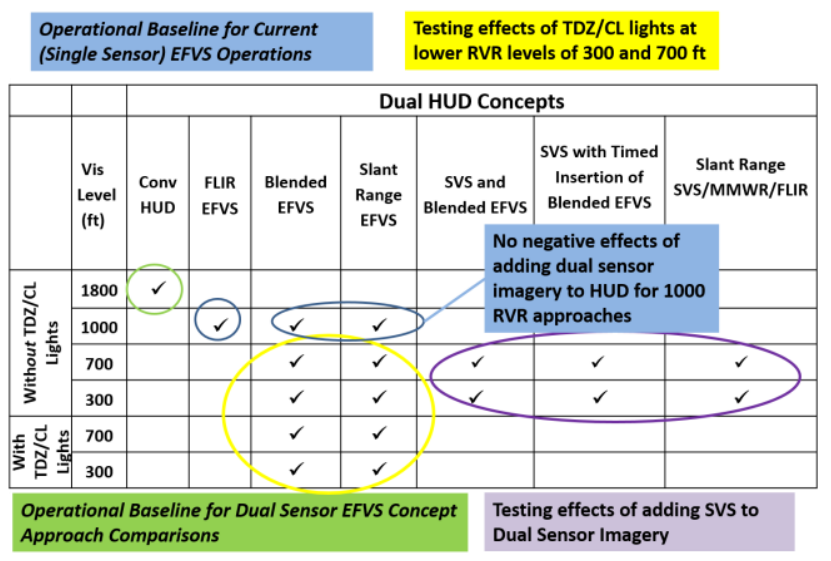

Figure 1. Nominal Approach Matrix

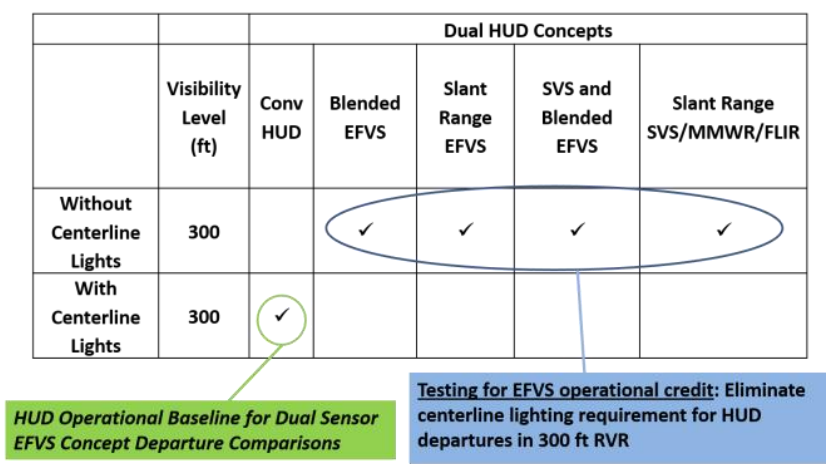

Figure 2. Nominal Departure Matrix

To enable the participants to more easily make comparisons on display concepts the RVR was blocked on both approach and departure runs so that participants were shown all concepts in one visual condition and then the other. The runs within each visibility block were randomized. The block order was also randomized. Total runs for each set of participants were 28 .

\section{Independent Variables}

The independent variables for approach were:

1) Seven HUD display concepts consisting of two baselines, two methods of displaying FLIR and MMWR information and three ways of combining synthetic vision information to the FLIR and MMRW display concepts

2) With and without touchdown and centerline lighting 
3) Four visibility conditions consisting of 1800, 1000, 700, and 300 RVR.

The independent variables for departure were:

1) Five HUD display concepts consisting of a baseline, two methods of displaying FLIR and MMWR information, and two methods of combining synthetic vision information to the FLIR and MMWR display concepts

2) With and without touchdown and centerline lighting

Figures 3 and 4 show the display conditions used in the study in 300 RVR with touchdown and centerline lighting on a representative approach at 100 feet above touchdown height.
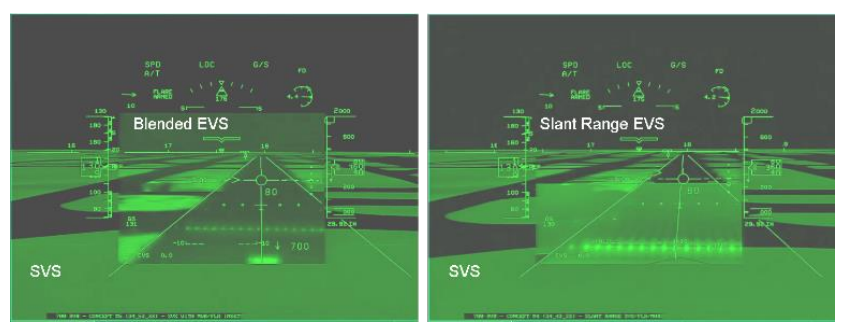

Figure 3. FLIR/MMWR EFVS HUD Concepts with Synthetic Vision: Blended (left side) and Slant Range (right side)

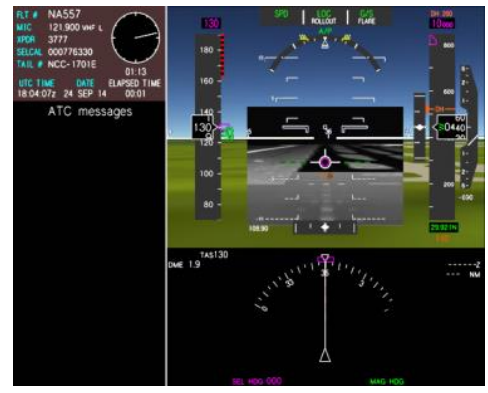

Figure 4. EFVS PFD Concept

\section{Dependent Variables}

The dependent variables included both objective and subjective measures. The objective variables included performance in the instrument segment from the start of the run until decision height (DH) as measured by root mean square (RMS) localizer deviation and RMS glide slope deviation statistics; performance in the visual segment from $\mathrm{DH}$ to threshold crossing measured by localizer and glide slope deviation statistics (mean, standard deviation, and maximum value) at 100 feet HAT and at threshold crossing; percentage of missed approaches; touchdown performance measured by longitudinal distance from threshold, distance from centerline, sink rate statistics, and touchdown roll angle/bank angle to asses wing/tail strike; and rollout and departure performance measured by deviation from centerline statistics (RMS and maximum distance from centerline). Subjective measures included postrun workload using the Air Force Flight Test Center $(\text { AFFTC })^{25}$ rating and Likert-type questions ${ }^{26}$ of the utility of the display concepts; post-test semi structured debriefing questions and discussion. NASA Task Load Index (TLX) ${ }^{27}$ was used for four approaches to gauge workload measures with more diagnosticity.

\section{Procedures}

Participants received an introductory briefing and informed consent, eye/head tracker calibration, extensive briefing of display concepts and procedures for EFVS approaches, simulation familiarization and training, two days of data collection, and a post-test interview and debrief. The training material included significant detail on all five display concepts and general procedures used for EFVS including required visual references needed to complete the approach using EFVS. Training consisted of cockpit familiarization and pointing out how the different image sources were affected by night and reduced visibility conditions. Autoland approaches were conducted using various visibility conditions encountered in the study with each of the five concepts. The participants were instructed to remove the HUD symbology and look only at the imagery for the autoland approaches. The crews then conducted hand-flown approaches with auto-throttles engaged for each of the five display concepts using the procedures and callouts expected for the study. A goaround was commanded by Air Traffic Control on the final approach run to train go-around procedures in the simulator. Initial training was done with motion off to facilitate the Principal Investigator (PI) standing and pointing out switches and display features. When the crew started hand-flying the approaches during training, the motion system was engaged. Departure training was conducted from the end of the runway with the last departure ending in an aborted takeoff initiated by the PI calling reject. 
All approaches were conducted to the Memphis International Airport north/south runways. Approaches to the north runways (36L, 36C, 36R) had touchdown zone, centerline, and Surface Movement Guidance and Control System (SMGCS) lighting on the ground including lead-on/lead-off lights and taxi centerline lighting; while approaches to the south runways (18L, 18C, 18R) did not. ALSF2 approach lighting systems (ALS) were used on the north runways and MALSR ALS were used on the south runways.

Data collection proceeded after the training runs were complete and a complete matrix of 28 runs was conducted. After each run, the AFFTC workload measures, ${ }^{25}$ see Figure 5, and Likert-type scale questionnaires, ${ }^{26}$ see Figures 6-8, were administered. Crews were handed sheets to quietly mark their individual ratings to remove experimenter and participant bias. Four times during the study, the NASA TLX $^{27}$ was administered to gather data on workload. The participants were queried by the PI and the scores were recorded. Upon completion of all runs, participants were debriefed with a guided questionnaire and semi-structured discussions. A pair-wise comparison was conducted ${ }^{24}$ to evaluate the PF and PM's subjective assessment of situation awareness for each of the five EFVS concepts flown in extremely low visibility conditions. The PF and PM were also asked to rank order the 5 EFVS concepts they evaluated in terms of preference for flying with in low visibility conditions.

\begin{tabular}{|c|l|}
\hline & \multicolumn{1}{|c|}{$\begin{array}{c}\text { AFFTC Workload Estimate } \\
\text { (On the sheet provided, write the number of the statement which best describes the } \\
\text { MAXIMUM workload you experienced during the past work period.) }\end{array}$} \\
\hline 1 & Nothing To Do; No System Demands \\
\hline 2 & Light Activity; Minimum Demands \\
\hline 3 & Moderate Activity; Easily Managed; Considerable Spare Time \\
\hline 4 & Busy; Challenging But Manageable; Adequate Time Available \\
\hline 5 & Very Busy; Demanding To Manage; Barely Enough Time \\
\hline 6 & Extremely Busy; Very Difficult; Non-Essential Tasks Postponed \\
\hline 7 & Overloaded; System Unmanageable; Important Tasks Undone \\
\hline \hline
\end{tabular}

\section{Figure 5. Air Force Flight Test Center Workload} Scale

\begin{tabular}{|c|c|c|c|c|c|c|c|}
\hline 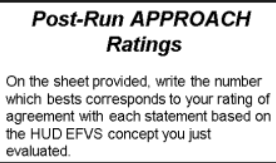 & $\begin{array}{c}\text { Strongly } \\
\text { Disagree } \\
1 \\
1\end{array}$ & $\begin{array}{l}\text { Disagree } \\
2\end{array}$ & $\begin{array}{c}\begin{array}{c}\text { Slightly } \\
\text { Disagree }\end{array} \\
3 \\
3\end{array}$ & \begin{tabular}{|c|}
$\begin{array}{c}\text { Neither } \\
\text { Agree or } \\
\text { Disagree }\end{array}$ \\
\\
4
\end{tabular} & $\begin{array}{c}\text { Slightly } \\
\text { Agree }\end{array}$ & $\begin{array}{c}\text { Agree } \\
6\end{array}$ & 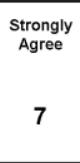 \\
\hline $\begin{array}{l}\text { Q1. Prior to DH, I was able to } \\
\text { pick up the necessary visual } \\
\text { references to continue the } \\
\text { approach or landing. }\end{array}$ & & & & & & & \\
\hline $\begin{array}{l}\text { Q2. The landing visual } \\
\text { references were visible and } \\
\text { identifiable no lower than } 100 \\
\text { ft AFL (i.e., the runway and } \\
\text { touchdown zone). }\end{array}$ & & & & & & & \\
\hline $\begin{array}{l}\text { Q3. There was sufficient time } \\
\text { to recognize and identify the } \\
\text { required visual references. }\end{array}$ & & & & & & & \\
\hline $\begin{array}{l}\text { Q4. The visual information } \\
\text { provided sufficient cues to } \\
\text { flare and land. }\end{array}$ & & & & & & & \\
\hline $\begin{array}{l}\text { Q5. I was able to maintain } \\
\text { lateral alignment with the } \\
\text { runway. }\end{array}$ & & & & & & & \\
\hline $\begin{array}{l}\text { Q6. I was able to complete the } \\
\text { approach and land safely. }\end{array}$ & & & & & & & \\
\hline
\end{tabular}

Figure 6. Post-Run Approach Questionaire

\begin{tabular}{|c|c|c|c|c|c|c|c|}
\hline $\begin{array}{l}\text { Post-Run TAXI } \\
\quad \text { Ratings } \\
\text { On the sheet provided, write the } \\
\text { number which bests corresponds } \\
\text { to your rating of agreement on the } \\
\text { HUDD EFVS concept you just } \\
\text { evaluated. }\end{array}$ & $\begin{array}{c}\text { Strongly } \\
\text { Disagree } \\
\\
1\end{array}$ & $\begin{array}{c}\text { Disagree } \\
2\end{array}$ & $\begin{array}{c}\begin{array}{c}\text { Slightly } \\
\text { Disagree }\end{array} \\
3 \\
3\end{array}$ & $\begin{array}{c}\text { Neither } \\
\text { Agree or } \\
\text { Disagree } \\
\\
4\end{array}$ & $\begin{array}{c}\text { Slightly } \\
\text { Agree }\end{array}$ & $\begin{array}{c}\text { Agree } \\
6\end{array}$ & $\begin{array}{c}\begin{array}{c}\text { Strongly } \\
\text { Agree }\end{array} \\
7\end{array}$ \\
\hline $\begin{array}{l}\text { Q1. EFVS improved my } \\
\text { ability to taxi. }\end{array}$ & & & & & & & \\
\hline $\begin{array}{l}\text { Q2. The Field-of-Regard } \\
\text { of the EFVS was } \\
\text { sufficient to taxi. }\end{array}$ & & & & & & & \\
\hline $\begin{array}{l}\text { Q3. I was able to safely } \\
\text { taxi the aircraft. }\end{array}$ & & & & & & & \\
\hline
\end{tabular}

Figure 7. Post-Run Taxi Questionaire

\begin{tabular}{|c|c|c|c|c|c|c|c|}
\hline $\begin{array}{l}\text { Post-Run } \\
\text { DEPARTURE } \\
\text { Ratings } \\
\text { on the sheet provided, write the } \\
\text { number which bests corresponds } \\
\text { to your rating of agreement on } \\
\text { the HUD EFVS concept you just } \\
\text { evaluated. }\end{array}$ & $\begin{array}{l}\text { Strongly } \\
\text { Disagree }\end{array}$ & $\begin{array}{c}\text { Disagree } \\
2\end{array}$ & $\begin{array}{c}\begin{array}{c}\text { Slightly } \\
\text { Disagree }\end{array} \\
\\
3\end{array}$ & $\begin{array}{c}\text { Neither } \\
\text { Agree or } \\
\text { Disagree } \\
\\
4\end{array}$ & $\begin{array}{c}\text { Slightly } \\
\text { Agree } \\
5 \\
5\end{array}$ & $\begin{array}{l}\text { Agree } \\
6\end{array}$ & $\begin{array}{c}\text { Strongly } \\
\text { Agree }\end{array}$ \\
\hline $\begin{array}{l}\text { Q1. I was able to } \\
\text { position the aircraft on } \\
\text { runway centerline using } \\
\text { the EFVS in preparation } \\
\text { for takeoff roll. }\end{array}$ & & & & & & & \\
\hline $\begin{array}{l}\text { Q2. I was able to } \\
\text { maintain centerline } \\
\text { during takeoff roll. }\end{array}$ & & & & & & & \\
\hline $\begin{array}{l}\text { Q3. I was able to } \\
\text { maintain runway } \\
\text { heading during initial } \\
\text { climbout. }\end{array}$ & & & & & & & \\
\hline $\begin{array}{l}\text { Q4. I was able to safely } \\
\text { complete the departure. }\end{array}$ & & & & & & & \\
\hline
\end{tabular}

Figure 8. Post-Run Departure Questionaire

\section{Apparatus}

The study was conducted in the NASA Langley Research Center (LaRC) Research Flight Deck (RFD) simulator. The study was conducted in full motion with the RFD articulated on top of a hexapod hydraulic motion system. The RFD is representative 
of a state-of-the-art advanced subsonic transport airplane with fully reconfigurable flight deck systems. The RFD is composed of a 200 degree $\mathrm{x} 40$ degree field-of-view out-the-window collimated scenery system. The flight deck includes three large landscape format Liquid Crystal Displays configured as two primary flight displays, two navigation displays and engine instruments and crew alerting system (EICAS) displays, cursor controllers, and multifunction controls on the center control stand. Electronic flight bag (EFB) displays are outboard on each pilot's side. Movable driven throttle system, including auto-throttles, is implemented. Active side stick controllers coupled side to side are provided for manual aircraft control. Dual HGS-6700 head-up displays are fitted with overhead brightness controls. A castle switch on the side-stick controls image and symbology on the HUD. Concepts to be studied were displayed on the both HUDs and PFDs as shown in Figure 9. Checklists and approach charts were available on the EFB.

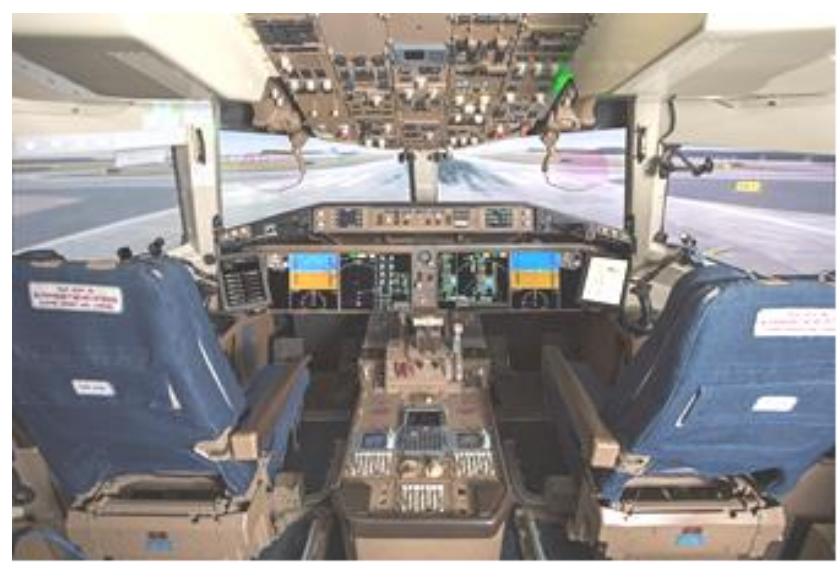

Figure 9. Research Flight Deck

Three detailed databases were developed for the study. ${ }^{24}$ First a detailed out-the-window visual database was created for the Memphis airport and surrounding area. All of the terrain features down to the foot level were modeled as well as roads and airport structures. From this detailed database, two additional databases were created using material codings for all objects to associate infrared (IR) and radar properties onto each feature. The IR database was rendered using standard tools developed by Rockwell Collins Simulation and Training Systems, modeling a short-wave/mid-wave cooled IR sensor. The MMWR simulation was rendered using a physics-based modeling process developed at NASA LaRC. This model produced a detailed 3D MMWR image that was mapped to a B scope image and then mapped back to lower resolution $\mathrm{C}$ scope image. Radar parameters simulated a $94 \mathrm{GHz}$ radar with a 5 mile range, using 5 meter range bins and $0.5 \mathrm{deg}$ angular width, simulating emerging 3D MMWR systems.

\section{Results}

Statistical results were evaluated in Minitab.

All landings, both nominal and those conducted during failure conditions, were within visual performance standards of the first third of the runway and within the lateral confines of the runway. All but three of the approximately 250 landings were within Category III autoland tolerance as defined in AC $120-28 \mathrm{D}^{26}$ and the All Weather Operations manual. ${ }^{27}$ Of those three, two were firm landings from the same crew in failure conditions and one was a landing too near the threshold in the baseline HUD symbolgyonly case in visual conditions of 1800 RVR.

No go-arounds occurred for any of the approaches except in response to failures and one scenario where a crew decided that traffic was still on the runway while on short final.

\section{Pilot-Flying HUD Failures}

To test the fail-operational concept of the operation and to determine crew response to failures, the pilot-flying HUD was randomly failed at 80 feet height above the threshold. A Blended EFVS concept in 300 RVR to Runway $18 \mathrm{~L}$ with 10 knots of left cross-wind was used. Proper crew response would be to go-around, continue head-down, or transfer control to the pilot monitoring to complete the landing. All but one of the crews conducted a go-around and Figure 10 shows the go-around results. Nominal threshold crossing was 50 feet and the failure occurred at 80 feet. Mean altitude when the TOGA button was pressed was around 80 feet and minimum altitude attained averaged around 45 feet. These altitude values represent a quick determination by the $\mathrm{PF}$ and a positive climb rate not long after threshold crossing. Eleven crews executed a timely go-around with no excursions from centerline tracking. 


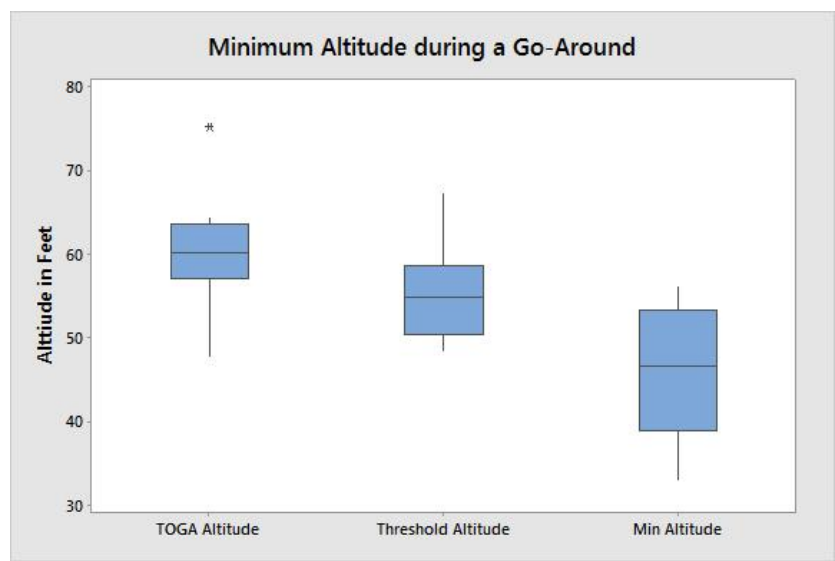

Figure 10. Box Plot of TOGA Altitude, Threshold Altitude, and Minimum Altitude

Table 1 shows the mean subjective ratings for $\mathrm{PF}$ and PM in response to the post-run questions (Figure 6). PFs rated their workload as being challenging but manageable during the complete failure of their HUD at $80 \mathrm{ft}$ AGL. PMs rated their workload as being easily handled during this failure of the PF's HUD. Both crew members slightly agreed that prior to $\mathrm{DH}$ they had sufficient time to recognize and identify the required visual references to continue the approach or landing in 300 RVR. The PFs agreed that the runway and touchdown zone required visual references were visible and identifiable by $100 \mathrm{ft}$ above field elevation.

\begin{tabular}{|l|l|l|}
\hline & PF ratings & PM ratings \\
\hline $\begin{array}{l}\text { AFFTC } \\
\text { Workload }\end{array}$ & 4.0 & 3.1 \\
\hline Approach Q1 & 5.3 & 5.1 \\
\hline Approach Q2 & 5.7 & 4.8 \\
\hline Approach Q3 & 5.3 & 4.8 \\
\hline
\end{tabular}

Table 1. Workload and Post-Run Approach Questionnaire Ratings for PF HUD Failure

One of the crews discussed the transfer of control idea over the course of the study and completed the transfer of control to a landing. With a sample size of one, only generalizations can be made with the data. Even just comparing the data within the crew doesn't work because the PM only made this one landing. An additional complicating factor is on this particular approach the pilot flying was 15 feet left of centerline at decision height. The landing was made well within the autoland criteria. There was up to 15 feet maximum lateral error during the landing rollout. The PM during the landing rated his workload as challenging but manageable, slightly agreed that he was able to complete the approach and landing safely, and agreed that the required visual references were available and adequate and he could maintain lateral alignment with the runway.

\section{Pilot Monitoring HUD Failures}

Since the pilot monitoring HUD failure was equivalent to a failure of the standby channel it was basically a non-event. No go-arounds were conducted for this failure and all 12 crews performed a successful landing. The failure was presented on the Slant Range concept in 700 RVR with 10 knots of right cross-wind to Runway 36R. To test for equivalent performance, a comparison was made with the exact same conditions except no failure and 5 knots of left cross-wind. Figure 11 shows lateral and vertical RMS errors in feet from decision height to touchdown. There was no significant $(p>0.05)$ differences in the vertical or lateral errors between the EFVS failure condition and the same EFVS concept with no failure.

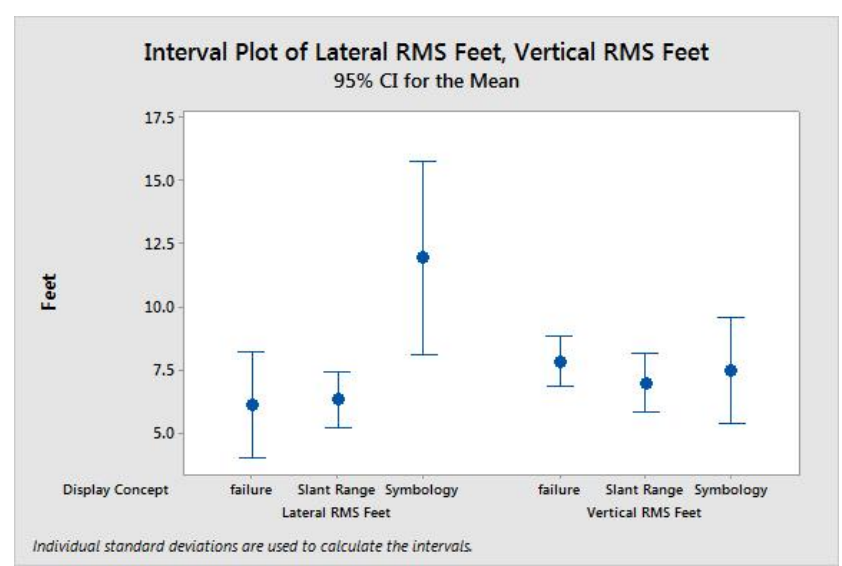

Figure 11. PM HUD Failure RMS Errors

Table 2 details subjective ratings for PF and PM during the failures. Both crew members rated their workload as being easily handled with adequate time available during this event. The PFs agreed that they had sufficient time to recognize and identify the required visual references to continue the approach or landing and the imagery provided them sufficient information to flare, land and maintain centerline in 700 RVR. The PFs strongly agreed that they were able to complete the approach and land safely even in the presence of a complete PM HUD failure. 


\begin{tabular}{|l|l|l|}
\hline & PF ratings & PM ratings \\
\hline Workload & 3.0 & 2.7 \\
\hline Approach Q1 & 6.2 & 5.8 \\
\hline Approach Q2 & 6.2 & 5.3 \\
\hline Approach Q3 & 6.2 & 5.7 \\
\hline Approach Q4 & 6.3 & 5.2 \\
\hline Approach Q5 & 6.4 & 5.9 \\
\hline Approach Q6 & 6.6 & 5.9 \\
\hline
\end{tabular}

Table 2. Workload and Post-Run Approach Questionnaire Ratings for PM HUD Failure

\section{EFVS System Failures}

Pilots were briefed that EFVS failures would be annunciated on the HUD and would trigger an EICAS caution alert. The response to a failure above decision height was a go-around. Failures below decision height did not require a go-around. For this study, the "EFVS Fail" message was triggered at 350 feet, which is above decision height, and the proper response would have been a go-around sometime before the decision height. The failure was an insidious failure since the system continued to operate normally until 80 feet where a complete EFVS system failure (symbology and imagery removed from HUD) occurred for both the PF and PM. "EFVS FAIL" was presented using the blended FLIR/MMWR concept, with and without synthetic vision, in $700 \mathrm{RVR}$ with 15 knots of left cross-wind to Runway 36C. Seven of twelve crews responded correctly and conducted a go-around before decision height. The performance is detailed in Figure 12. One crew didn't conduct a go-around until the second failure at 80 feet and it was a successful maneuver. Four of the twelve crews disregarded the second failure and completed the landing with a blank HUD using available (700 RVR with touchdown zone and centerline lighting) out the window visibility cues. Since there are a limited number of landings and this landing case represent an operational scenario that cannot be allowed to happen, no statistical analysis was conducted for the landings.

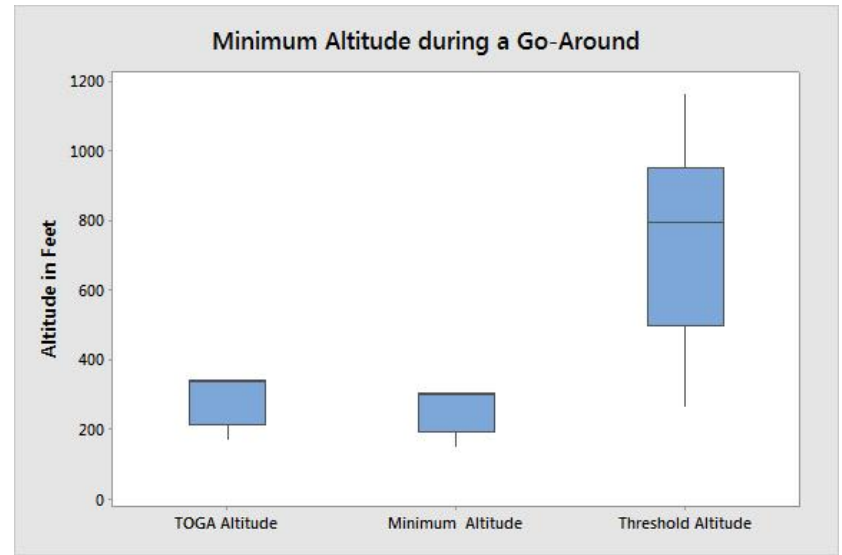

Figure 12. Interval Plot of TOGA Altitude, Minimum Altitude, and Threshold Altitude for EFVS Failure

Crews rated their workload (mean=3.5) as requiring moderate activity to being busy during the annunciated EFVS HUD failure.

\section{Departures}

Take-offs were conducted in 300 feet of visibility with five knots of crosswind. A symbology only baseline was tested with runway centerline lighting as currently allowed under special authorization. EFVS concepts were tested with no runway centerline lighting. Failure conditions consisted of left engine failures at 100 knots using symbology only and Slant Range concepts. Figure 13 shows the absolute value of maximum distance from centerline and RMS values of centerline deviations (both measured in feet) during takeoff to gauge centerline tracking. A paired $\mathrm{T}$ test between failure conditions showed no significant difference $(p=0.135)$ but a paired $T$ test between each failure condition and the EFVS concepts with no failures showed a significant difference $(p=0.006$ for each pair) and a significant difference between the symbology only baseline $(\mathrm{p}=0.004)$. Centerline tracking for the normal departures showed no significant $(p>0.05)$ differences compared to the symbology only departure even though the EFVS departures did not have centerline lighting. None of the departures had excursions beyond operational significance and any lateral excursions during engine failures were quickly corrected to centerline. 


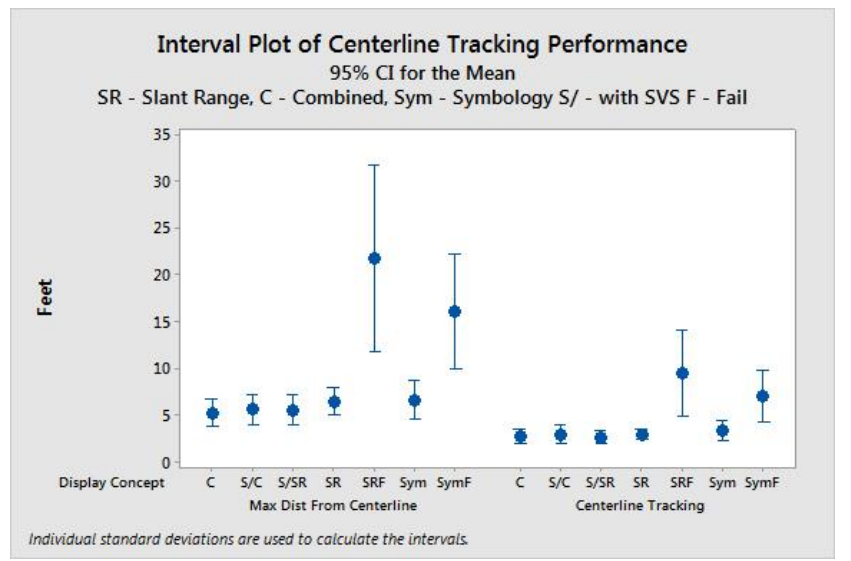

Figure 13. Departure Performance in Feet from Centerline

Having imagery during a rejected takeoff appears to have slightly decreased the PF's workload. With imagery, PFs rated (mean workload=3.4) the task as requiring moderate activity but with considerable spare time to attend to other tasks. Without imagery, the PFs rated their workload (mean $=3.8)$ as being challenging but manageable and with adequate time available to attend to other tasks. Comparable workload for the PM was found with either the Conventional HUD or Slant Range HUD as PMs rated their workload (mean=3.0) as being easily managed during the rejected takeoff runs.

\section{Discussion}

Universally, all pilots had high praise for the EFVS concepts. All concepts worked equally well. Although this paper details the non-normal conditions, a short discussion of the normal landings is provided with no supporting data. There was a pilot preference for a combination of synthetic vision combined with sensor information but there was no difference in performance with or without synthetic vision for the landing tasks. There was a tight grouping of touchdown dispersions. No difference was noted between the 700 foot or 300 foot visibility cases. The data supports RTCA DO-341 and the operational feasibility of approach, landing, and rollout in visibilities as low as 300 RVR. Performance was at least as good as or better than currently approved EFVS operations in higher visibilities (1000 RVR with FLIR) and better than the symbology only (1800 RVR) case with touchdown zone and centerline lighting infrastructure required.
The study attempted to determine if the failoperational concept detailed in RTCA DO-341 was operationally feasible. Pilots were briefed and trained that for any failure of the HUD they could transition to head-down, they could transfer control to the other pilot, or they could go-around. They were to choose the safest course of action.

In the event of a PF HUD failure, 11 of the 12 crews performed a go-around. While safe, this procedure somewhat defeats the purpose of a failoperational system design. Only one crew picked up on the discussion enough to continue the discussion amongst themselves. They were a business jet crew where the authority gradient is often more level than the airlines. They received the PF HUD failure on the first day and at the start of the second day had clearly discussed it over the evening. They asked if the pilot monitoring could perform one training landing, and the request was granted. When they received the failure, they transferred control and performed a successful landing. Although there was a slight excursion from centerline during the transition, the landing was well within autoland certification criteria. Since only one landing was attempted, no real conclusion can be drawn from the objective data. The PF was 15 feet left of centerline at decision height, the PM landed within 2 feet of centerline and then crossed 15 feet right of centerline on rollout before correcting back to centerline. The entire excursion could be due to the initial lateral error at DH. The other eleven crews conducted a smooth and immediate go-around in response to the failure. No crews attempted to transition head-down and since they weren't trained for that transition, this result was not unexpected.

During post-run interviews, all pilots commented that transferring control to the other pilot at low altitude was not allowed in standard operating procedures. Many pilots indicated that airline procedures would not allow transfer of control below 500 feet and some even indicated not below 1,000 feet. Airline pilots commented that typically low visibility approaches would be flown by the captain and they would not transfer control to the co-pilot. Since neither a monitored approach (Captain monitors a co-pilot flying) nor transfer of control to a co-pilot is acceptable, the ability to transition headdown to the PFD with a sensor view is something that will have to be explored in the future. The PM 
HUD failure was essentially a failure in the standby channel of the total system. Except for the distraction of the monitoring pilot announcing a failure, performance was as good as the same condition without a failure. The only difference was in the wind condition where no failure was 10 knots of left crosswind and the failure condition was in 10 knots of right crosswind. Figure 11 details RMS errors in the visual segment from 200 feet above the runway to touchdown. Using RMS errors to remove the wind effects, there was no performance difference for the failure compared to the same EFVS concept with no failure in either the vertical or lateral dimensions. Subjective ratings support no difference in performance between failures and non-failures in the monitoring pilot. This does support the fail-operation conclusion for monitoring failures.

EFVS system failures were not always handled correctly. Although the failures were discussed in training and briefings, the failures were not trained or practiced in the simulator. Seven of twelve crews performed a correct and successful go-around, see Figure 12. One of the crews performed a go-around around 70 feet above the runway when the image blanked for the second failure and four crews decided at the second failure that they had sufficient visual cues to complete a successful landing in 700 foot visibility with touchdown zone and centerline lighting. The EFVS fail annunciation on the HUD did not flash or become boxed as normal because the software could not be easily changed. The EICAS fail annunciation was near the top of the EICAS display and a number of crews said it was too high to be easily seen. All of these items could have been covered in training but the experimenters felt this would eliminate the element of surprise when the failure occurred. For an operational system, the design methodology and crew procedures for a failoperational vision system would have to be wellengrained in training.

Normal take-off tracking was good for all concepts, see Figure 13. Centerline tracking performance did not degrade for EFVS with no centerline lighting compared to symbology-only with centerline lighting.

There was a significant effect in centerline tracking performance during engine failures at 100 knots. This result was not unexpected since just the initial yawing from the engine failure alone would cause some lateral errors. Successful certification criteria during failures for departure is that the aircraft must not depart the runway and tracking back to centerline is smooth after any excursions. All of the failure departures resulted in all of the crews correctly determining that the engine had failed with an appropriate rejected takeoff below V1. None of the failure cases resulted in an excursion off the runway. There was no significant difference between the EFVS failures on a runway with no centerline lighting and the baseline symbology-only case with centerline lighting. Subjectively, pilots indicated departure operations using EFVS was operationally feasible. This performance was probably, in fact, conservative because of an unexpected simulator mechanization fault in the hexapod motion base and the brake models. The rejected takeoff and normal maximum manual braking moved the hexapod to the forward stop during the initial deceleration. This action caused a sudden stop and shudder in the flight deck and produced a significant startle effect that happens right during the time that rudder corrections needed to be made to return to centerline. The result was an initial removal from the brakes and rudder pedals that probably resulted in more lateral excursion than normal.

\section{Conclusion}

This study supports the operational feasibility of conducting approach, landing and rollout to a safe taxi speed in visibilities as low as 300 RVR using Enhanced Flight Vision Systems (EFVS). All twelve crews universally decided that the system provided all the visual cues required in the visual segment at or before the decision height to continue for a landing. Many crews had the required references as early as 500 feet. Most crews commented they wanted this system immediately and it was a significant improvement over current low visibility landing systems. Success was independent of visibility. All concepts of EFVS, with and without synthetic vision, performed equally well. Landing performance was independent of approach lighting and touchdown zone and centerline lighting systems. Performance was improved over current Special Category I operations of HUD symbology with 1800 RVR with touchdown zone and centerline lighting, even in 300 RVR conditions with no centerline lighting. 
The fail-operational concept needs further study. It is clear that depending on the pilot monitoring to take control during failures is not operationally feasible - at least, as it is currently trained and implemented in today's low visibility approach procedures. Using the head-down display, if designed correctly, may provide a fail-operational path for the PF. Additionally, the HUD for the PM provides the capability to call excursions during failures and to safely complete the operation during pilot incapacitation or landing errors. This was not studied and would require additional investigation. Failpassive operations, potentially even in $300 \mathrm{RVR}$, could be feasible since the pilot is actively in the loop hand flying and a go-around is a natural response to any detected failure. The failures chosen for the study were felt to be the worst failures to handle. They resulted in a complete loss of function of visual and symbology elements by failing the complete HUD. This complete loss of information did result in an immediate and easily recognizable failure, so additional study is required using more subtle failures. The authors have evaluated frozen images and even those failures are immediately recognizable by pilots but all potential failures would need to be evaluated. Training on system failures and the proper procedural aspects of those failures is required. A number of crews ignored failure messages. Operationally all failure annunciations on the HUD should flash and be boxed to capture the pilots attention. This study did not do that because of software change limitations.

Departures were made safely using EFVS concepts, even on runways with no additional lighting infrastructure, with an equivalent level of safety as compared to today's operations in both normal and failure conditions. This outcome may allow future operations using EFVS systems for departure credit. Engine failures were evaluated at 100 knots but no failures were evaluated at or beyond V1. It is not expected that failures at or above V1 would be a problem but is something that requires future study to ensure there are no issues. No failures were evaluated in the EFVS or HUD images for departures and would require further study.

Taxi was not an investigative part of the study, but taxi operations were observed for runway exit and turnoff toward correct taxi clearance as well as taxi to the runway during departure scenarios. Crews described taxi operations as normal and they were able to perform turns even with significant oversteer in $300 \mathrm{RVR}$.

\section{References}

[1] Lindberg, Charles, 1953, The Spirit of St. Louis, New York, NY, Scribner, pg. 131.

[2] Joint Planning and Development Office, 2008, Next Generation Air Transportation System Integrated Plan: A Functional Outline, Washington, DC.

[3] Federal Aviation Administration, Instrument Flight Procedures (IFP) Inventory Summary, Retrieved April 27, 2015 from http://www.faa.gov/air traffic/flight info/aeronav/ifp inventorysummary.

[4] Federal Aviation Administration, NextGen Implementation Plan 2014, Retrieved June 15, 2015 from

http://www.faa.gov/nextgen/library/media/nextgen_i mplementation_plan_2014.pdf

[5] Schnell, Thomas, Mike Keller, Tim Etherington, 2009, Trade-offs in Synthetic Vision Systems Display Resolution, Field of Regard, Terrain Data Density, Texture, and Shading During Off Path Operations, The International Journal of Aviation Psychology, pp. 33-48

[6]Arthur, Trey, Lance Prinzel, Lynda Kramer, Randall Bailey, and Russ Parrish, 2003, CFIT Prevention Using Synthetic Vision, Proceedings of SPIE, Enhanced and Synthetic Vision 2003, 5018, pp. 146-157.

[7] Schiefele, Jens, Duncan Howland, JphnMaris, Christian Pschierer, Patrick Wipplinger, Michael Meuter, 2005, Human factors flight trial analysis for 3D SVS: Part II. Proceedings of SPIE, Enhanced and Synthetic Vision 2005, 5802, pp. 195-206.

[8] Theunissen, Erik, Fenne Roefs, Tim Etherington, 2009, Synthetic Vision: Application Areas, Rationale, Implementation, and Results, The International Journal of Aviation Psychology, pp. 832

[9] Kramer, Lynda, Lance Prinzel, Randall Bailey, and Trey Arthur, 2003, Synthetic Vision Enhances 
Situation Awareness and RNP Capabilities for Terrain-challenged Approaches, Proceedings of the American Institute of Aeronautics and Astronautics Third Aviation Technology, Integration, and Operations Technical Forum, AIAA 2003-6814, pp. $1-11$.

[10] Guy French, Thomas Schnell, 2003, Terrain Awareness \& Pathway Guidance for Head-up Displays (TAPGUIDE): a Simulator Study of Pilot Performance, Proceedings of 22nd IEEE/AIAA Digital Avionics Systems Conference, 2, pp. 9.C.4 9.1-7.

[11] Katherine Lemos, Thomas Schnell, 2003, Synthetic Vision Systems: Human Performance Assessment of the Influence of Terrain Density and Texture. Proceedings of 22nd IEEE/AIAA Digital Avionics Systems Conference, 2, pp. 9.E.3 - 91-10.

[12] Alexander, Amy, Christopher Wickens, Thomas Hardy, 2005, Synthetic Vision Systems: The Effects of Guidance Symbology, Display Size, and Field of View, Human Factors, Winter 2005 Vol. 47 Issues 4, pp. 693

[13] Kramer, Lynda, Stephen Williams, Randall Bailey, 2008, Simulation Evaluation of Synthetic Vision as an Enabling Technology for Equivalent Visual Operations. Proceedings of SPIE, Enhanced and Synthetic Vision Conference 2008, 6957, pp. 115.

[14] McKenna, Ed, 2012, Synthetic Vision Systems, Avionics Magazine, May 2012, pp. 20-23.

[15] Connor, Glenn, 2011, On the Road to Zero-Zero, Professional Pilot Magazine, April 2011.

[16] Minimum Aviation System Performance Standards (MASPS) for Enhanced Vision Systems, Synthetic Vision Systems, Combined Vision Systems and Enhanced Flight Vision Systems. RTCA/DO315, RTCA Inc. Washington, DC. Dec 2008.

[17] Federal Aviation Administration, Revisions to Operational Requirements for the Use of Enhanced Flight Vision Systems (EFVS) and to Pilot Compartment View Requirements for Vision Systems, Retrieved April 27, 2015 from https://federalregister.gov/a/2013-13454.
[18] Glenn Connor, 2014, NASA Studies Advanced EFVS Sensor Models with Dual HUD Flightdeck for Landing in $300 \mathrm{ft}$ RVR, Professional Pilot, October 2014, pp. 98-102.

[19] Bailey, Randal, Lynda Kramer, Stephen Williams, 2010), Enhanced Vision for All-weather Operations under NextGen, Proceedings of SPIE Enhanced and Synthetic Vision Conference 2010, 7689, pp. 768903-1-768903-18.

[20] Kramer, Lynda, Randall Bailey, Kyle Ellis, Stephen Williams, Trey Arthur, Lance Prinzel, Kevin Shelton, 2013, Enhanced Flight Vision Systems and Synthetic Vision Systems for NextGen Approach and Landing Operations (NASA Technical Publication 218054), Washington, DC: NASA

[21] Shelton, Kevin, Lynda Kramer, Kyle Ellis, Stephanie Rehfeld, 2012, Synthetic and Enhanced Vision Systems for NextGen (SEVS) Simulation and Flight Test Performance Evaluation, Proceedings of the 31st Digital Avionics Systems Conference, 2D51-2D5-12.

[22] Kramer, Lynda, Stephanie Harrison, Randall Bailey, Kevin Shelton, Kyle Ellis, 2014, Visual Advantage of Enhanced Flight Vision System during NextGen Flight Test Evaluation, Proceedings of SPIE Degraded Visual Environments: Enhanced, Synthetic, and External Vision Solutions 2014, 9087, pp. 90870G-90870G-18.

[23] Minimum Aviation Systems Performance Standard (MASPS) for an Enhanced Flight Vision Systems to Enable All-Weather Approach, Landing, and Rollout to a Safe Taxi Speed, RTCA/DO-341, RTCA Inc. Washington, DC Sept 2012

[24] Kramer, Lynda, Timothy Etherington, Kurt Severance, Randall Bailey, Steven Williams, Stephanie Harrison, 2015, Assessing Dual Sensor Enhanced Flight Vision Systems to Enable Equivalent Visual Operations, AIAA, October 2015

[25] Ames, Lawrence, Edward George, 1993, Revision and Verification of a Seven-point Workload Estimation Scale. Air Force Flight Test Center: AFFTC-TIM-93-01.

[26] Vidulich, Michael, Edward Hughes, 1991, Testing a Subjective Metric of Situation Awareness, 
Proceedings of the Human Factors \& Ergonomics Society, 35th Annual Meeting, pp. 1307-1311.

[27] http://humansystems.arc.nasa.gov/groups/tlx/

[28] Federal Aviation Administration Advisory Circular: Criteria for Approval of Category III Weather Minima for Takeoff, Landing, and Rollout, AC-120-28D, Dated July 13, 1999.

[29] European Aviation Safety Agency, Joint Aviation Requirements, All-Weather Operations. Amendment 4, Dated February, 2007.

\section{Acknowledgements}

This work was sponsored by NASA's Aviation Safety Program (AvSP), Vehicle Systems Safety Technologies project, led by Mr. Paul Krasa, Project Manager. The authors would like to thank the civil servants and contractors in NASA Langley's Simulation Development Branch who provided excellent simulation development, maintenance, and execution in support of our experiment. The support and advice from Mr. Glenn Connor, Discover Technologies, Mark Humphries, FAA Long Beach ACO, and Mr. Kevin Burnett and Mr. Jack Cross, Sierra Nevada Corporation was greatly appreciated.

\section{Email Addresses}

timothy.j.etherington@nasa.gov

lynda.j.kramer@nasa.gov

kurt.severance@nasa.gov

34th Digital Avionics Systems Conference

September 13-17, 2015 